\title{
Inter-Comparison of Land Surface Model Soil Moisture Data with Traditional Soil Dryness Indices
}

\author{
I. Dharssi $^{\mathrm{a}}$ and Vinodkumar ${ }^{\mathrm{b}}$ \\ ${ }^{a}$ Bureau of Meteorology, Melbourne, Victoria, Australia \\ ${ }^{\mathrm{b}}$ Bushfire and Natural Hazards Cooperative Research Centre, Melbourne, Victoria, Australia \\ Email: i.dharssi@bom.gov.au
}

\begin{abstract}
Australia has a long history of frequent forest fires, owing to its hot and dry climate. The McArthur Forest Fire Danger Index (FFDI; McArthur, 1967) was introduced in 1958 for operational fire warnings over Australia and is still used operationally, albeit with continuous development. The formulation of FFDI is based on air temperature, wind speed, relative humidity, and a component representing fuel availability called the Drought Factor (DF). The DF is defined on the assumption that the fuel moisture content (FMC) is affected by both long term and short term drying effects. The short term drying effects are based on the time since recent rain and past 20 days rainfall amount. The long term drying effects are based on either the KeetchByram Drought Index (KBDI; Keetch and Byram, 1968) or Mount's Soil Dryness Index (MSDI; Mount, 1972). KBDI and MSDI are estimates of the cumulative soil moisture deficit (SMD) and represent the degree of drought in the landscape. Studies show that the occurrence of large destructive fires corresponds to very large SMD values. SMD therefore is a key variable in the FFDI calculations with accurate estimates of soil moisture crucial for effective wildfire management, rating and warning. The KBDI is widely used in the Australian states of Victoria, New South Wales and Queensland while MSDI is used in the states of Tasmania, South Australia and Western Australia (Finkele et al., 2006).

KBDI and MSDI are simple water balance models that do not take into account the majority of physical factors which affect soil moisture dynamics such as soil type, vegetation type, terrain or aspect. They over-simplify the evapotranspiration and runoff processes, which are critical in calculating accurate soil moisture states, leading to large errors. Recent progresses in the remote sensing of soil moisture, data assimilation techniques and physically based land surface models has led to the development of new soil moisture products. Two examples of such datasets are the soil moisture analyses produced from the Bureau of Meteorology's operational Numerical Weather Prediction (NWP) system and remotely sensed soil wetness measurements from the Advanced Scatterometer (ASCAT; Wagner et al., 2013) instrument. This study undertakes an evaluation of the latter two datasets along with KBDI, MSDI and another simple water balance model called the Antecedent Precipitation Index (API; Crow et al., 2005). In-situ observations of soil moisture from the OzNet hydrological monitoring network (Smith et al., 2012) and Australian national cosmic ray soil moisture monitoring facility (CosmOz; Hawdon et al., 2014) are used to validate the modelled and remotely sensed soil moisture datasets.

The verification shows that the NWP soil moisture analyses have greater skill and smaller biases than the KBDI, MSDI and API analyses. This is despite the NWP system having a coarse horizontal resolution and not using observed precipitation. The average temporal correlations between observed $\mathrm{CosmOz}$ and modelled soil moisture are $0.81,0.63,0.76$ and 0.73 for NWP, KBDI, MSDI and API. Verification also shows that the remotely sensed Advanced Scatterometer soil wetness product is of good quality. This study suggests that analyses of soil moisture can be greatly improved by using physically based land surface models, remote sensing measurements and data assimilation.
\end{abstract}

Keywords: Soil moisture, verification, wild fire, ASCAT, KBDI 


\section{Data And Methodology}

\subsection{Meteorologically Based Soil Moisture Indices}

This study calculates gridded daily analyses of KBDI and MSDI using the same methodology as Finkele et al. (2006). The primary difference is that this study calculates KBDI and MSDI at a resolution of about $5 \mathrm{~km}$ while Finkele et al. (2006) calculated KBDI and MSDI at a resolution of about $25 \mathrm{~km}$. KBDI and MSDI are calculated using gridded analyses of daily rainfall and daily maximum temperature from the Australian Water Availability Project (AWAP; Jones et al., 2009). The AWAP gridded analyses are based on observations of precipitation and temperature and also have a resolution of about $5 \mathrm{~km}$. The gridded fields of KBDI and MSDI are computed for 40 years, from 1974 to 2014. A spin-up period of 10 years, from 1964 to 1974 is used.

Keetch-Byram Drought Index. The KBDI (Keetch and Byram, 1968) is a simple water balance model to estimate soil moisture depletion in the upper soil levels. The underlying assumptions of KBDI are that (i) the rate of moisture loss due to evapotranspiration is a function of vegetation cover density, which itself is an exponential function of mean annual rainfall, (ii) the evapotranspiration rate is also assumed to be an exponential function of the daily maximum temperature, and (iii) the depth of the soil layer is such that the maximum moisture available is $203 \mathrm{~mm}$.

Mount's Soil Dryness Index . MSDI (Mount, 1972) was developed for the Tasmanian Fire Service as an alternative to KBDI. Rainfall interception and runoff in MSDI are based on seven vegetation categories. For each vegetation class, parameter values are defined for canopy rainfall interception fraction, canopy storage capacity, canopy loss per wet day, and flash-runoff fraction (Finkele et al., 2006). The regression coefficients used to calculate evapotranspiration are the same as those used operationally by the Bureau of Meteorology's MSDI calculations.

Antecedent Precipitation Index • API is another simple water balance model (Crow et al., 2005) and is based on the assumption that the amount of moisture in a soil column is related to precipitation at earlier times. API for day $i$ is given by: $\mathrm{API}_{i}=\gamma \mathrm{API}_{i-1}+P_{i}$. Following Crow et al. (2005), the loss coefficient $\gamma=0.85+0.0075\left(293.15-T_{\max }\right)$ where $P_{i}$ is the daily precipitation $(\mathrm{mm})$ and $T_{\max }$ is the daily maximum temperature (Kelvin).

\subsection{In situ Soil Moisture Observations}

OzNet. The OzNet hydrological monitoring network is managed together by Monash University and University of Melbourne in Australia. Soil moisture observations from the Murrumbidgee river catchment (Fig. 1a; Smith et al., 2012) are available online for the period 2001 to 2011. Soil moisture observations from the top $30 \mathrm{~cm}$ are used in this study for comparisons with models. The Murrumbidgee catchment is characterised by significant spatial variability in climate, soil, vegetation and land use. Climate variations are mainly associated with the change in elevation from west to east, which varies from $50 \mathrm{~m}$ to more than $2000 \mathrm{~m}$. Soil types are predominantly of finer-texture in the plains of the western half of the catchment, whereas the eastern half is primarily dominated by medium to coarse-textured soils.

CosmOz. CosmOz is a network of cosmic ray soil moisture probes established at thirteen locations around Australia. A cosmic-ray probe measures the number of fast neutrons near the land surface. Fast neutrons are strongly moderated by the presence of hydrogen and soil moisture represents the largest and most variable source of hydrogen near the surface. One advantage over traditional point measurement sensors is that cosmic-ray probes have a much larger horizontal footprint of about $660 \mathrm{~m}$ in diameter at sea level. CosmOz observations are obtained from the online portal managed by Commonwealth Scientific and Industrial Research Organisation (CSIRO) of Australia. This study uses seven hour moving averages of level 4 processed data which are available directly from the portal. The data processing and calibration methods used by the CosmOz network are described by Hawdon et al. (2014).

\subsection{NWP Soil Moisture}

The operational global NWP system employed by the Bureau of Meteorology is part of the Australian community Climate and Earth System Simulator (ACCESS). The ACCESS Global NWP system first became operational in September 2009 with a horizontal resolution of about $80 \mathrm{~km}$. The ACCESS Global NWP system was updated in March 2012 with an increase in horizontal resolution to about $40 \mathrm{~km}$. Numerous improvements to the ACCESS model and data assimilation were also implemented. The ACCESS Global NWP 
(a) OzNet

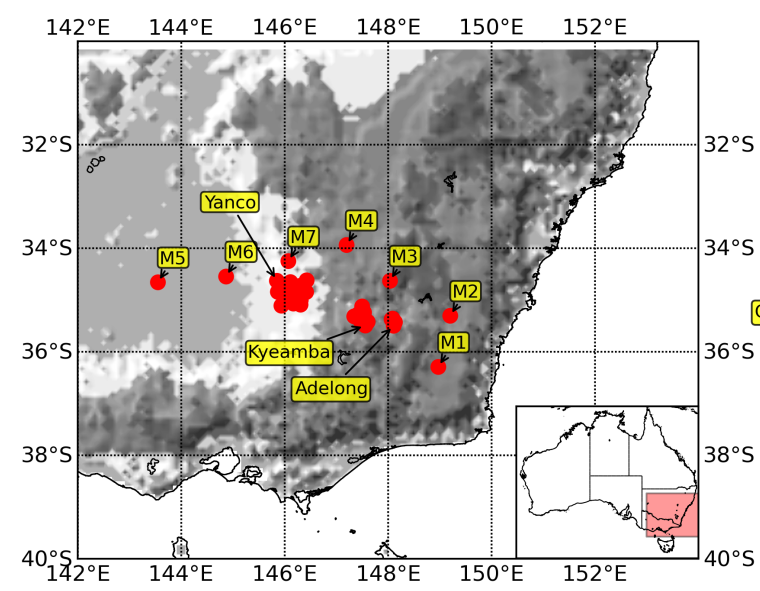

(b) $\mathrm{CosmOz}$

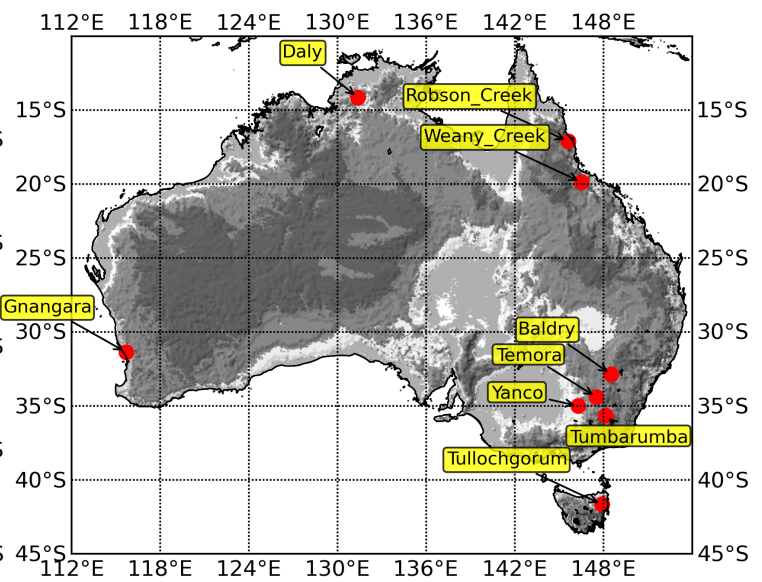

Figure 1. Site locations of (a) OzNet and (b) CosmOz network observing stations. Spatial extent of OzNet is shown by the map of Australia in the inset of (a). The filled contours represent surface elevation $(\mathrm{m})$ at

$10 \mathrm{~km}$ resolution.

system does not use observations of precipitation. This study refers to the old ACCESS Global NWP system as ACCESS_80km and the newer ACCESS Global NWP system as ACCESS_40km.

ACCESS NWP incorporates a physically based land surface model (LSM) and soil moisture is one of the prognostic variables simulated. Both ACCESS_80km and ACCESS_40km use the Met Office Surface Exchange Scheme version $2 \mathrm{LSM}$. The MOSES2 soil is $3 \mathrm{~m}$ thick and is discretised into four layers of $0.1,0.25,0.65$ and $2 m$ thickness from top to bottom.

ACCESS Global NWP employs a physically based soil moisture nudging technique (Best et al., 2007) that adjusts the model soil moisture to minimise the errors in six hour forecasts. The soil moisture nudging scheme only uses observations of screen level temperature and humidity and doesn't use any remotely sensed observations or any observed precipitation.

The ACCESS_80km soil moisture analyses are only available from 2009 to 2012. ACCESS_40km soil moisture analyses are only available from 2012. ACCESS_40km soil moisture analyses can be compared with CosmOz observations which are available in near real-time (NRT) since 2011. The ACCESS NWP soil moisture content analyses $\left(\mathrm{SMC}_{i}\right.$ ) have units of mass per unit area $\left(\mathrm{kg} / \mathrm{m}^{2}\right)$. While the soil moisture observations are in units of volumetric fraction $\left(\mathrm{m}^{3} \mathrm{~m}^{-3}\right)$. Two alternative methods are used to convert to soil moisture volumetric fraction $(\theta)$. For simplicity, the Static Weight (SW) method uses $\theta=\left(\mathrm{SMC}_{1}+\mathrm{SMC}_{2}\right) /\left(\rho_{w}\left[d_{1}+d_{2}\right]\right)$. $\rho_{w}=1000 \mathrm{~kg} / \mathrm{m}^{2}$ is the density of water and $d_{i}$ is the thickness of the ACCESS NWP soil layer $i\left(d_{1}=0.1 \mathrm{~m}\right.$ and $\left.d_{2}=0.25 \mathrm{~m}\right) . \quad \mathrm{SMC}_{i}$ is the ACCESS soil moisture content in ACCESS NWP soil layer $i$. The Dynamic Weight (DW) method uses the approach of Franz et al. (2012);

$$
\theta=\frac{\sum_{i} W_{i} \mathrm{SMC}_{i} / d_{i}}{\rho_{w} \sum_{i} W_{i}}
$$

The value of the weights $W_{i}$ depends on the reported sensing depth of the CosmOz observing system.

\subsection{ASCAT soil water index}

The Advanced Scatterometer (ASCAT) instruments on board EUMETSAT meteorological satellites MetOpA (launched 2006) and MetOp-B (launched 2012) provides NRT estimates of surface soil wetness. A third ASCAT instrument is expected to be launched on the MetOp-C satellite during 2017, thereby providing a continuous and long-term source of NRT soil moisture measurements. This study uses the EUMETSAT NRT $12.5 \mathrm{~km}$ resolution product from MetOp-A. 
Table 1. Verification scores for the ACCESS NWP models (ACCESS_80km and ACCESS_40km), KBDI, MSDI, API and ASCAT against OzNet and CosmOz in situ soil moisture observations. Scores for both normal and anomaly time series are presented. The values represent an observing network average. The ACCESS_40km uses the dynamic weighting method. A x symbol represents an unavailable value.

\begin{tabular}{c|cc|cc|cc||ccc}
\hline Data set & \multicolumn{4}{|c}{ Correlation } & \multicolumn{2}{c}{ Bormal Time Series } & \multicolumn{2}{c}{ Rias } & \multicolumn{2}{c}{$\begin{array}{c}\text { Anomaly Time Series } \\
\text { Correlation }\end{array}$} \\
& OzNet & CosmOz & OzNet & CosmOz & OzNet & CosmOz & OzNet & CosmOz \\
\hline ACCESS_80km & 0.72 & $\mathrm{x}$ & 0.02 & $\mathrm{x}$ & 0.19 & $\mathrm{x}$ & 0.68 & $\mathrm{x}$ \\
ACCESS_40km & $\mathrm{x}$ & 0.81 & $\mathrm{x}$ & -0.03 & $\mathrm{x}$ & 0.15 & $\mathrm{x}$ & 0.68 \\
KBDI & 0.64 & 0.63 & -0.26 & -0.22 & 0.36 & 0.32 & 0.72 & 0.47 \\
MSDI & 0.71 & 0.76 & -0.02 & -0.07 & 0.22 & 0.20 & 0.75 & 0.50 \\
API & 0.66 & 0.73 & 0.14 & 0.14 & 0.26 & 0.23 & 0.71 & 0.68 \\
ASCAT & $\mathrm{x}$ & 0.81 & $\mathrm{x}$ & -0.01 & $\mathrm{x}$ & 0.19 & $\mathrm{x}$ & 0.67 \\
\hline
\end{tabular}

Table 2. Verification scores for normalised ACCESS_40km soil moisture analyses against ground based CosmOz observations. SW (DW) represents the static (dynamic) weighting method.

\begin{tabular}{|c|c|c|c|c|c|c|c|c|c|c|c|}
\hline \multirow[t]{2}{*}{ Site } & \multicolumn{3}{|c|}{ Sensing Depth $(m)$} & \multicolumn{2}{|c|}{ Correlation } & \multicolumn{2}{|c|}{ Bias } & \multicolumn{2}{|c|}{ RMSD } & \multicolumn{2}{|c|}{ Anomaly Correlation } \\
\hline & Mean & Max & Min & SW & DW & SW & DW & SW & DW & SW & DW \\
\hline Baldry & 0.22 & 0.38 & 0.11 & 0.89 & 0.87 & 0.02 & 0.01 & 0.11 & 0.13 & 0.83 & 0.80 \\
\hline Daly & 0.40 & 0.55 & 0.16 & 0.82 & 0.84 & -0.02 & -0.03 & 0.13 & 0.13 & 0.60 & 0.61 \\
\hline Gnangara & 0.40 & 0.56 & 0.24 & 0.57 & 0.66 & -0.07 & 0.05 & 0.21 & 0.19 & 0.52 & 0.66 \\
\hline Robson Creek & 0.13 & 0.21 & 0.08 & 0.80 & 0.82 & 0.06 & -0.06 & 0.16 & 0.15 & 0.40 & 0.45 \\
\hline Temora & 0.17 & 0.27 & 0.09 & 0.90 & 0.90 & -0.01 & -0.05 & 0.12 & 0.13 & 0.72 & 0.77 \\
\hline Tullochgorum & 0.20 & 0.47 & 0.08 & 0.76 & 0.75 & 0.09 & 0.00 & 0.18 & 0.16 & 0.66 & 0.71 \\
\hline Tumbarumba & 0.10 & 0.14 & 0.06 & 0.81 & 0.81 & 0.04 & -0.05 & 0.16 & 0.16 & 0.49 & 0.54 \\
\hline Weaney Creek & 0.23 & 0.35 & 0.11 & 0.74 & 0.75 & -0.02 & -0.05 & 0.15 & 0.17 & 0.77 & 0.78 \\
\hline Yanco & 0.20 & 0.37 & 0.08 & 0.87 & 0.88 & -0.03 & -0.05 & 0.13 & 0.13 & 0.76 & 0.77 \\
\hline Mean & & & & 0.80 & 0.81 & 0.01 & -0.03 & 0.15 & 0.15 & 0.64 & 0.68 \\
\hline
\end{tabular}

Exponential Filter. The ASCAT surface soil wetness product represents soil moisture in a thin surface layer of $\simeq 1 \mathrm{~cm}$ thickness (Albergel et al., 2012). However, the in-situ observations and model analyses of soil moisture used in this study are for a deeper layer of soil. Therefore, the exponential filter (Wagner et al., 2013) is applied to the time-series of ASCAT surface soil wetness measurements to approximate the soil wetness profiles (SWI) for a deeper layer of soil. A recursive formulation of the exponential filter is used in this study.

\subsection{Data processing}

In order to match the daily time steps of the API, KBDI and MSDI analyses, the NWP model soil moisture analyses, ASCAT soil wetness measurements and in situ soil moisture observations are converted to daily averages. The nearest neighbour technique is used to co-locate the data. KBDI and MSDI values are converted to soil moisture content by subtracting the values from their respective maximum.

\subsection{Verification Metrics}

The approach of Albergel et al. (2012) is used to calculate the soil moisture verification statistics. To enable a fair comparison, all soil moisture time-series are normalised between $[0,1]$ using their own maximum and minimum values from their own long time series, as also done by many other soil moisture verification studies.

The anomaly correlations between models and observations are also calculated. Anomalies are computed for each time-series by using a 31-day sliding window to calculate the window mean $\left(\bar{\theta}_{i}\right)$. The anomaly $A$ is then computed using $A_{i}=\theta_{i}-\bar{\theta}_{i}$.

\section{Results}

Verification against OzNet is only carried out for ACCESS_80km, API, KBDI and MSDI, since their temporal availability overlaps with that of the OzNet observations. The verifications statistics are calculated from 
September 2009 to May 2011 when all the data are available. The evaluation against CosmOz is undertaken for ACCESS_40km, ASCAT, API, KBDI and MSDI. Since ACCESS_40km dataset has the shortest availability, the verification period spans from May 2012 to Dec 2014.

\subsection{Comparison with OzNet}

Normal time series. The verification with respect to the OzNet sites are given in Table 1 and represent averages over 30 stations. Results show that ACCESS_80km soil moisture analyses have the best overall agreement with the OzNet soil moisture observations. The ACCESS_80km soil moisture analyses have the smallest bias and RMSD and the highest temporal correlation. KBDI displays a large wet bias at all stations suggesting that KBDI underestimates evapotranspiration. MSDI shows a small average wet bias, but doesn't systematically exhibit a wet bias at all stations. These results suggest that the MSDI analyses are more accurate than KBDI primarily because KBDI shows a significant wet bias. Figure 2 shows a Taylor diagram comparing model soil moisture against OzNet soil moisture observations at the 30 stations.

Anomaly time series. The short term variation in model soil moisture is assessed through verification of anomaly time-series. Such short term soil moisture variations may be significant for calculation of fire danger, particularly for Australia, where heatwaves can cause rapid drying. Finkele et al. (2006) find that the DF in FFDI increases too quickly during periods of prolonged dryness after a significant rain event. They show that this problem can be addressed by using SMD rather than past rainfall to calculate short term drying. Mean soil moisture anomaly correlation between model and in-situ observations are presented in Table 1 . The results suggest that ACCESS_80km is better able to capture the soil moisture seasonal variations rather than the short term variations.

\subsection{Comparison with $\mathrm{CosmOz}$}

Normal time series. The soil moisture analyses from ACCESS_40km, KBDI, MSDI, API and ASCAT are evaluated against daily average measurements from the CosmOz cosmic ray probes. Although there are a total of 13 sites in the CosmOz observing network, only the nine sites which are fully calibrated and are not subjected to irrigation are selected (Fig. 1b) for this study. Measurements from Gnangara are included even though there are major issues with site calibration (Hawdon et al., 2014).

Table 2 shows the verification scores at CosmOz locations using either the static (ACCESS_SW) or dynamic (ACCESS_DW) weighted ACCESS_40km NWP soil moisture. The scores for ACCESS_SW and ACCESS_DW are similar at most locations. ACCESS_SW only uses information from the top two model soil layers while ACCESS_DW can also use information from the third model soil layer, when the CosmOz sensing depth is greater than $0.35 \mathrm{~m}$.

The verification shows that ACCESS NWP (ACCESS_40km) soil moisture analyses have the best overall agreement with the CosmOz soil moisture observations. The ACCESS_40km soil moisture analyses have the smallest bias and RMSD and the highest temporal correlation. The results also suggest that ACCESS_40km soil moisture analyses agree more closely with the in-situ observations than ACCESS_80km soil moisture analyses. Since, the difference in temporal correlation between ACCESS_40km and MSDI (0.81 vs 0.76) is greater than the difference in temporal correlation between ACCESS_80km and MSDI (0.72 vs 0.71). KBDI again shows a rather large wet bias over all stations. Since the CosmOz observations are scattered all over Australia, this implies that KBDI under-predicts the soil moisture deficit substantially, regardless of the climate zone. API, unlike KBDI, exhibits a dry bias at all CosmOz sites. MSDI doesn't exhibit any consistent wet or dry bias. API has similar, but slightly worse, skill to MSDI. API gives an average correlation of 0.73 , which is greater than KBDI (0.63) but less than MSDI (0.76).

ASCAT skill is generally very good with temporal correlations greater than 0.8 , except at the Tumbarumba and Tullochgorum observing stations. The Tumbarumba site is located in a eucalyptus forest and the Tullochgorum site is surrounded by high terrain. ASCAT has difficulties in measuring soil moisture accurately in regions with high vegetation density or complex terrain (Dharssi et al., 2011).

Anomaly time series. Table 1 shows mean anomaly correlation between CosmOz observations and models. The ACCESS_DW, API and ASCAT best captures the short term soil moisture variations. The mean anomaly correlations are 0.68 (API), 0.68 (ACCESS_DW), 0.50 (MSDI) and 0.47 (KBDI). The mean anomaly correlation between CosmOz and ASCAT is 0.67. Mean anomaly correlation between KBDI and CosmOz observations is significantly lower than the mean anomaly correlation between KBDI and OzNet observations. 

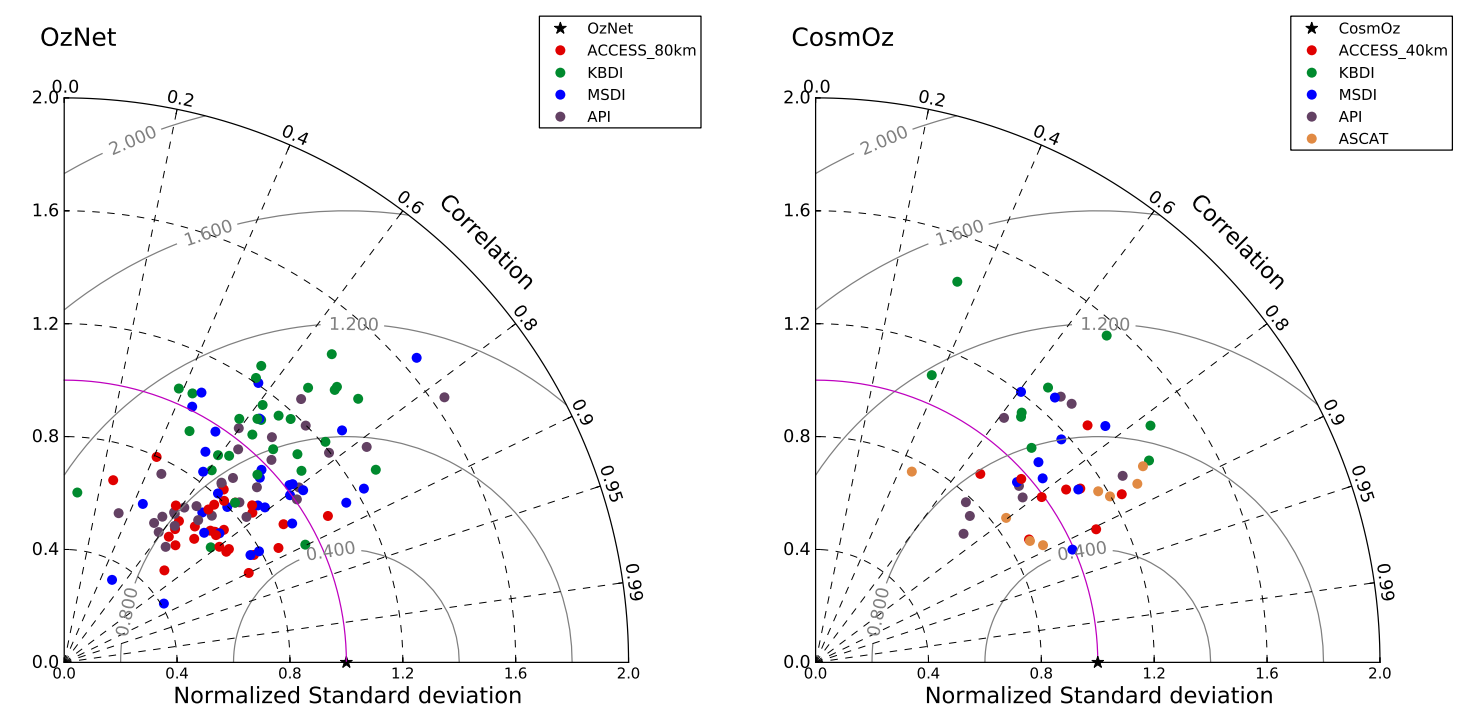

Figure 2. Taylor diagrams. Left Panel shows the verification scores of ACCESS_80km (red dots), KBDI (green dots) and MSDI (blue dots) against soil moisture observations at 30 OzNet observing stations. Right panel shows the verification scores of ACCESS_40km (red dots), KBDI (green dots), MSDI (blue dots), API (greyish purple dots) and ASCAT (orange dots) against soil moisture observations from nine CosmOz sites. ACCESS_40km uses the dynamic weighting method.

Most likely, this is due to sensor locations. The OzNet Y10 site and CosmOz Yanco sites are located nearby and show similar anomaly correlation values. Anomaly correlation values are 0.59 (OzNet Y10 vs KBDI) and 0.55 (CosmOz Yanco vs KBDI).

\section{Conclusions}

This is one of very few studies to compare and verify KBDI and MSDI against ground based soil moisture observations. It is already widely known that KBDI indicates significantly wetter conditions than MSDI (Finkele et al., 2006). However, until now, it has not been known which is less accurate. The verification results in this study clearly shows that KBDI has a large wet bias and that MSDI agrees more closely with ground based soil moisture observations. KBDI is found to have a large wet bias at all the OzNet and CosmOz observing stations used for verification. The results also show that overall MSDI has a small wet bias. However, at many observing stations MSDI has a dry bias. Moreover, the verification results show that KBDI and MSDI have limited skill.

This is the first study to verify ACCESS NWP soil moisture analyses against ground based observations. This is also one of the first studies to use CosmOz soil moisture observations for verification. Comparison against observations shows that ACCESS NWP soil moisture analyses have more skill than KBDI and MSDI. This is despite the fact that KBDI and MSDI are computed on a much higher resolution grid and use observation based rainfall and temperature analyses. ACCESS NWP has a much coarser resolution and doesn't use any observations of precipitation. Results show that the ACCESS NWP soil moisture analyses have small biases and are particularly good at capturing the seasonal variations. Results also indicate that the more recent ACCESS_40km model soil moisture analyses agree more closely with the in-situ observations than the older ACCESS_80km model. This is likely to be due to the higher spatial resolution of ACCESS_40km as well as improvements to the model and data assimilation. As well as higher accuracy, the ACCESS NWP system is much more flexible and provides analyses of soil moisture on four clearly defined soil layers over a $3 \mathrm{~m}$ depth of soil. In contrast, the simple water balance model outputs are ambiguous since the assumed depth of soil is not clearly defined. Another significant advantage of ACCESS NWP is the ability to produce 10 day forecasts of soil moisture. Such forecasts will be very useful for medium range forecasting of fire risk. Future work is planned to assess the skill of the 10 day soil moisture forecasts. The ACCESS NWP system is in the midst of an upgrade that will increase the horizontal resolution to $25 \mathrm{~km}$. 
The best way to improve the analyses of SMD for operational fire warnings is to combine the strengths of the different systems. The major strength of ACCESS NWP is that it uses a physically based land surface model and data assimilation which allows ACCESS NWP to accurately capture the soil moisture seasonal variations and minimise biases. The simple water balance models, particularly API, do a good job of capturing the short term soil moisture variations because they have a high spatial resolution and use observations based rainfall and temperature analyses. Therefore, we propose to develop a soil moisture analysis scheme that uses: (i) A physically based land surface model driven by observation based rainfall and temperature, running at a high spatial resolution of about $5 \mathrm{~km}$, (ii) A land surface data assimilation scheme to assimilate remotely sensed observations such as ASCAT.

Replacing the over-simplified KBDI and MSDI indices with more accurate analyses of SMD is an important step forward. However, it is important to note that more accurate analyses of SMD may not automatically lead to more accurate operational fire warnings. There may be significant biases and errors in the method used to derive the DF from the input SMD and recent rainfall. The FFDI uses DF (and not SMD) as one of the inputs. Therefore, additional work is likely to be required to improve the method used to calculate the DF. The long term goal is to replace the DF with a more physically based method to calculate fuel moisture content from SMD and remotely sensed vegetation information.

\section{REFERENCES}

Albergel, C., P. de Rosnay, C. Gruhier, J. Muoz-Sabater, S. Hasenauer, L. Isaksen, Y. Kerr, and W. Wagner, 2012: Evaluation of remotely sensed and modelled soil moisture products using global ground-based in situ observations. Remote Sensing of Environment, 118, 215 - 226.

Best, M., C. Jones, I. Dharssi, and R. Quaggin, 2007: A physically based soil moisture nudging scheme for the global model. Technical report, Met Office, Exeter, UK.

Crow, W., R. Bindlish, and T. Jackson, 2005: The added value of spaceborne passive microwave soil moisture retrievals for forecasting rainfall-runoff partitioning. Geophysical Research Letters, 32.

Dharssi, I., K. J. Bovis, B. Macpherson, and C. P. Jones, 2011: Operational assimilation of ASCAT surface soil wetness at the Met Office. Hydrology and Earth System Sciences, 15, 2729-2746.

Finkele, K., G. A. Mills, G. Beard, and D. A. Jones, 2006: National gridded drought factors and comparison of two soil moisture deficit formulations used in prediction of Forest Fire Danger Index in Australia. BMRC research report 119, Bureau of Meteorology, Melbourne, Australia.

Franz, T. E., M. Zreda, R. Rosolem, and T. Ferre, 2012: Field validation of a cosmic-ray neutron sensor using a distributed sensor network. Vadose Zone Journal, 11.

Hawdon, A., D. McJannet, and J. Wallace, 2014: Calibration and correction procedures for cosmic-ray neutron soil moisture probes located across Australia. Water Resources Research, 50, 5029-5043.

Jones, D. A., W. Wang, and R. Fawcett, 2009: High-quality spatial climate data-sets for Australia. Australian Meteorological and Oceanographic Journal, 58, 233.

Keetch, J. J. and G. M. Byram, 1968: A drought index for forest fire control. Research Paper SE-38, USDA Forest Service: Asheville, NC, USA.

McArthur, A. G., 1967: Fire behaviour in eucalypt forests. Leaflet 107, Department of National Development Forestry and Timber Bureau: Canberra, Australia.

Mount, A., 1972: The derivation and testing of a soil dryness index using run-off data. Technical report, Tasmanian Forestry Commission, Hobart, Tasmania.

Smith, A., J. Walker, A. Western, R. Young, K. Ellett, R. Pipunic, R. Grayson, L. Siriwardena, F. Chiew, and H. Richter, 2012: The Murrumbidgee soil moisture monitoring network data set. Water Resources Research, 48.

Wagner, W., S. Hahn, R. Kidd, T. Melzer, Z. Bartalis, S. Hasenauer, J. Figa-Saldaña, P. de Rosnay, A. Jann, S. Schneider, et al., 2013: The ASCAT soil moisture product: A review of its specifications, validation results, and emerging applications. Meteorologische Zeitschrift, 22, 5-33. 